\title{
Effects of group composition on the incidence of respiratory afflictions in group-housed calves after weaning
}

\author{
A. Bach, ${ }^{*} \dagger^{1}$ C. Tejero, $\neq$ and J. Ahedoł \\ *ICREA (Institució Catalana de Recerca i Estudis Avançats), 08010 Barcelona, Spain \\ †Department of Ruminant Production, IRTA (Institut de Recerca i Tecnologia Agroalimentàries), 08140 Caldes de Montbui, Spain \\ ‡Rancho Las Nieves, 50550 Mallén, Spain
}

\section{ABSTRACT}

A study consisting of 2 experiments was conducted with the aim of determining the effects of previous history of bovine respiratory disease (BRD) on animal performance and health status of transition calves housed in groups. In both experiments, calves were housed in individual hutches until weaning age at $58 \mathrm{~d}$. Before weaning, BRD incidences were individually recorded on a daily basis. Following weaning, calves were moved into super hutches in groups of 8 , based on their history of respiratory afflictions, and growth performance and BRD incidences were recorded for $57 \mathrm{~d}$. In experiment 1, 144 female Holstein dairy calves (initial $\mathrm{BW}=72.6 \pm$ $1.2 \mathrm{~kg}$; age $=58.5 \pm 0.8 \mathrm{~d}$ ) were distributed in 6 super hutches composed of 8 calves with no previous history of BRD (HHH), 6 super hutches composed of 6 calves without and 2 calves with a previous episode of BRD (HHR), and 6 super hutches housed 5 calves without a history of BRD and 3 calves with previous respiratory afflictions (HRR). In experiment 2, 144 Holstein female calves $[58.0 \pm 0.9 \mathrm{~d} ; 72.5 \pm 0.9 \mathrm{~kg}$ of body weight $(\mathrm{BW})]$ were distributed in 2 treatments consisting of 9 super hutches housing integrally 8 calves with no previous BRD, and 9 super hutches housing integrally calves with a previous BRD case. The number of BRD cases after weaning progressively increased from $\mathrm{HHH}$ to HRR as the proportion of calves previously affected by BRD within super hutch increased, mainly due to the fact that both animals affected by BRD before weaning and those with no previous history of BRD had more relapses in HHR and HRR groups than in the $\mathrm{HHH}$ group. Odds of incurring BRD after grouping were 3.89 greater in calves that had a previous case of BRD than in those that did not. The average time elapsed between commingling the animals and the appearance of the first BRD case was shorter when calves that had at least one

\footnotetext{
Received August 9, 2010.

Accepted January 5, 2011.

${ }^{1}$ Corresponding author: alex.bach@irta.es
}

BRD episode prior to weaning were present in a group $(10.8 \pm 3.3 \mathrm{~d})$ than when the group was formed with calves that had never experienced BRD before weaning $(22.5 \pm 3.3 \mathrm{~d})$. Final BW (at $115 \mathrm{~d}$ of life) and average daily gain tended to decrease as the number of BRD cases incurred increased. In experiment 2 , calves in the $\mathrm{HHH}$ group reached a greater BW at the end of the study than those in the RRR group and tended to have a greater average daily gain in the $\mathrm{HHH}$ group than in the RRR group. It is concluded that forming groups of animals with a previous BRD history should minimize the incidence of respiratory cases in those groups of calves formed by animals without a previous history of respiratory disease.

Key words: transition, health, bovine respiratory disease

\section{INTRODUCTION}

Most dairy enterprises raise calves in individual hutches while providing milk or milk replacer (MR) and then move them into groups of different sizes after weaning. The main purpose for housing calves individually is to minimize spread of diseases. Infectious diseases (mainly diarrhea and respiratory upsets) are the most important illnesses affecting calves around weaning (Sivula et al., 1996; Virtala et al., 1996). Incidence of bovine respiratory disease (BRD) has been reported to be directly related to group size of calves (Martin and Meek, 1986; Svensson et al., 2003), and for this reason, it has been recommended to keep group size to about 6 to 10 animals (Svensson and Liberg, 2006; Bach and Ahedo, 2008). In addition, it has been reported (Bach et al., 2010) that moving calves into groups at pre-weaning time (when MR offer is decreased) improves calf performance and diminishes BRD incidence. Alternatively, in beef production systems, evidence exists that the health status and origin of the calves being commingled seems to be important in determining BRD incidence (Step et al., 2008), and, thus, grouping calves according to origin and BRD history may diminish morbidity after 
grouping. However, to our knowledge no study has been conducted in dairy replacement heifers to assess the effect of grouping calves after weaning based on their history of respiratory disease during the pre-weaning period. Therefore, the objective of this study was to evaluate the effects on performance and respiratory health of mixing calves after weaning according to the BRD history of each calf prior to weaning.

\section{MATERIALS AND METHODS}

\section{Animals and Treatments (Experiment 1)}

Two hundred and forty female Holstein calves (11.5 $\pm 0.8 \mathrm{~d}$ of age and $41.4 \pm 0.5 \mathrm{~kg}$ of $\mathrm{BW}$ ) were raised in individual hutches in a commercial contract heifer operation (Rancho Las Nieves, Mallén, Spain) and were checked for respiratory afflictions once daily starting at $5 \mathrm{~d}$ of age. Calves were individually housed in covered hutches $(1.1 \times 1.6 \mathrm{~m})$, which were bedded with straw once every other day. Calves had ad libitum access to water and a starter $(20.7 \% \mathrm{CP}, 20.5 \% \mathrm{NDF}, 3.9 \%$ fat, DM basis) and received $2 \mathrm{~L}$ of a MR $(25 \% \mathrm{CP}, 2 \%$ NDF, $19.2 \%$ fat, DM basis) at 15\% DM twice daily $(0700$ and $1700 \mathrm{~h})$ until the age of $49 \mathrm{~d}$. At that time, calves received $2 \mathrm{~L}$ of $\mathrm{MR}$ (also at $15 \% \mathrm{DM}$ ) only at $0800 \mathrm{~h}$ until weaning at $58 \mathrm{~d}$ of age. At weaning, calves were moved in groups of 8 animals into straw-bedded super hutches $(6 \times 3 \mathrm{~m})$. Animals had free access to a dry TMR (18.5\% CP, $27.5 \%$ NDF, $3.6 \%$ fat, DM basis). Water was provided ad libitum via one water bowl for each super hutch.

The study was conducted in 3 periods, with 48 calves (and 6 super hutches) per period. Out of the 240 initial calves, 144 were chosen to participate in the study based on the existence or absence of a respiratory case during the first $58 \mathrm{~d}$ of study. At weaning time $(58.5 \pm 0.8 \mathrm{~d}$; $72.6 \pm 1.2 \mathrm{~kg}$ of $\mathrm{BW}$ ) calves were allocated into different groups of 8 calves based on their previous BRD history. Within each period, 2 super hutches housed 8 calves with no previous record of BRD (HHH), 2 super hutches were composed of 6 animals with no previous BRD record and 2 calves with a previous episode of BRD (HHR), and 2 super hutches housed 5 calves without a history of BRD and 3 calves with previous respiratory afflictions (HRR). Animals with a previous BRD case were selected and then randomly allocated to either treatment HHR or HRR. Calves with no previous BRD record were randomly allocated to $\mathrm{HHH}$, HHR, or HRR groups. No calf had signs of BRD when groups were formed (animals with BRD signs at weaning time did not participate in the study). The experiment was completed when calves reached $115 \mathrm{~d}$ of age.

\section{Animals and Treatments (Experiment 2)}

Two hundred and forty female Holstein calves (12.8 $\pm 0.4 \mathrm{~d}$ of age and $42.6 \pm 0.3 \mathrm{~kg}$ of BW) were raised in individual hutches in a commercial contract heifer operation (Rancho Las Nieves, Mallén, Spain). Calves were fed and managed as described in experiment 1. The experiment was conducted in 3 periods, with 48 calves (and 6 super hutches) per period. Out of the 240 initial calves, 144 were chosen to participate in the study, based on the existence or absence of BRD during the first $58 \mathrm{~d}$ of study. Within each period, at weaning time $(58.0 \pm 0.9 \mathrm{~d} ; 72.5 \pm 0.9 \mathrm{~kg}$ of BW $)$, calves with no previous record of BRD (HHH) were randomly allocated to 3 super hutches containing 8 calves, and calves with a previous case of BRD were randomly allocated to 3 different super hutches (RRR). As in experiment 1 , no calf had signs of BRD when the groups were formed and the experiment was completed when calves reached $115 \mathrm{~d}$ of age.

\section{Measurements (Experiments 1 and 2)}

All calves were weighed at weaning time ( $58 \mathrm{~d}$; prior to forming groups) and at the end of the study at $115 \mathrm{~d}$ of age to determine growth performance. Two experienced veterinarians recorded incidences of respiratory afflictions daily throughout the study. Signs considered indicative of BRD (for calves individually and group housed) included abnormal apathy, depression, arched back, difficulty in getting up and lying down, difficulty in breathing, excessive nasal mucous secretions, and noisy breathing. In addition, rectal temperature of suspect animals was determined, and calves with temperatures above $40^{\circ} \mathrm{C}$ and showing any of the signs described above were considered as undergoing a BRD case and treated with $1 \mathrm{~mL}$ of $\mathrm{Nu}-$ flor $/ 13.6 \mathrm{~kg}$ of BW (Schering-Plough Animal Health Corp., Barcelona, Spain). Calves that showed signs of BRD but had no fever were treated with Ainil (Ketoprofen; Invesa, Barcelona, Spain) at the rate of 3 $\mathrm{mL} / 100 \mathrm{~kg}$ of BW. For the purposes of this study, all animals that were treated for BRD, independently of whether they had a fever, were considered as having BRD. Calves with a fever that did not respond to first antibiotic treatment were then treated with Micotil (Elanco Animal Health, Greenfield, IN) at the rate of $10 \mathrm{mg} / \mathrm{kg}$ of BW plus $3 \mathrm{~mL} / \mathrm{kg}$ of $\mathrm{BW}$ of Ainil (Invesa). Calves needing a third treatment received Resflor (Intervet/Schering-Plough Animal Health, Boxmeer, the Netherlands) at the rate of $3 \mathrm{~mL} / \mathrm{kg}$ of BW. Antibiotic treatments continued until rectal temperature was below $39.5^{\circ} \mathrm{C}$. 


\section{Calculations and Statistical Analysis (Experiments 1 and 2)}

The incidence of respiratory afflictions within super hutch was calculated as the proportion of animals that had any respiratory affliction during the study (from 58 to $115 \mathrm{~d}$ of life). The time elapsed since the groups were formed and the first respiratory case occurred was also calculated for each calf and averaged within super hutch. Similarly, the time elapsed between a first and a second case of BRD was calculated for each animal and averaged within super hutch.

Calves participating in the 2 experiments came from 120 different farms (58 in experiment 1 and 62 in experiment 2). To assess whether farm origin was a predisposing cause for BRD (due, for instance, to poor colostrum feeding practices), a mixed-effects logistic regression model was run with origin as the independent factor, incidence of BRD as the dependent variable, and period as a random factor using Stata software (Stata Corporation, 2006). Because the effect of origin was not significant, it was excluded from the rest of statistical analysis.

Primary outcome variables included animal performance, BRD incidence (proportion of calves affected and number of cases per super hutch), and risk of incurring BRD (odds ratio). Animal performance and BRD incidence were analyzed with SAS (SAS; Cary, NC) using a mixed-effects model with treatment as a fixed effect and period as a random effect. The number of BRD cases per hutch was analyzed using a mixedeffects Poisson regression analysis for count data with period as a random effect, and treatment as a fixed effect using Stata software (Stata Corporation, 2006). The experimental unit for all analyses was the super hutch. When designing the experiment, a power analysis with an $\alpha$ of 0.05 and a power of 0.8 indicated that for animal performance (mixed-effects model), 6 replicates would allow detection of differences in ADG above 150 $\mathrm{g}$ if the standard error was 0.05 . For differences in proportions (i.e., incidence of BRD), a sample of 6 would allow detection of differences between 2 proportions if the distance between the 2 was greater than 0.35 .

In addition, the effect of having BRD before grouping on growth performance, BRD incidence (proportion of calves affected and number of cases within super hutch), time to first BRD, and time between first and second BRD were assessed after removing all calves with a previous BRD case before weaning from the data set, summarizing again the data by super hutch, and then applying a mixed-effects model that accounted for the random effect of period, and the fixed effect of treatment. The same procedure was performed, but removing all data from heifers that never had BRD before grouping. With these data, the odds of having a BRD case was estimated fitting a mixed-effects logistic regression model with period as a random effect, and treatment as fixed effect using Stata software (Stata Corporation, 2006).

Lastly, BRD effect on animal performance (ADG between 58 and $115 \mathrm{~d}$ of life, and final BW at $115 \mathrm{~d}$ of life) was assessed using calf as the experimental unit. A mixed-effects model that accounted for the random effects of super hutch and period, and the fixed effects of number of BRD incurred after grouping was fitted using SAS (SAS; Cary, NC).

\section{RESULTS AND DISCUSSION}

Overall, BRD incidence between 12 and $58 \mathrm{~d}$ of age (while calves were individually hutched) was $14.2 \%$. This figure is similar to that reported in a recent study from the University of Guelph, Ontario, Canada (Stanton et al., 2010) in calves of similar age and housing conditions. Calf origin (or owner) per se was not a predisposing factor $(P=0.37)$ for BRD (data not shown). Main differences across origins would be the quality, quantity, and method of colostrum feeding. However, studies on the effect of colostrum quality and supply on BRD incidence are inconsistent, with some reporting no relationship (Berge et al., 2009) and some describing a beneficial effect of adequate colostrum feeding on BRD incidence (Wittum and Perino, 1995).

\section{Experiment 1}

Overall, BRD incidence after grouping calves was $37.9 \%$. Interestingly, on average, BRD incidence in this study was similar to that reported by Step et al. (2008) when mixing 8-mo-old steers from several farm origins, despite the age differences between the 2 studies. In the current study, as the proportion of animals with a previous BRD case increased in a super hutch, a tendency $(P=0.10)$ was observed for the proportion of calves newly affected by BRD to increase (Table 1). This increase was, in part, due to a tendency $(P=0.10)$ for the proportion of calves with no previous history of BRD that suffered BRD while grouped to increase as the number of calves previously affected by BRD within a super hutch increased (Table 1). In fact, the odds ratio for a calf with no previous BRD history to incur BRD when placed in the HRR group was numerically 2.85 times greater $(P=0.12)$ than when placed in the HHH group (data not shown). Furthermore, the overall odds of incurring BRD after grouping were 3.89 greater $(P<0.01)$ in calves that had a previous case of BRD than in those that did not (data not shown). In fact, the number of BRD cases after weaning progres- 
Table 1. Effects of clinical respiratory history of individually housed calves on incidence of bovine respiratory disease (BRD) after grouping (experiment 1)

\begin{tabular}{|c|c|c|c|c|c|}
\hline \multirow[b]{2}{*}{ Item } & \multicolumn{3}{|c|}{ Grouping strategy $^{1}$} & \multirow[b]{2}{*}{$\mathrm{SE}$} & \multirow[b]{2}{*}{$P$-value ${ }^{2}$} \\
\hline & $\mathrm{HHH}$ & HHR & HRR & & \\
\hline Proportion of calves with previous BRD affected by BRD, \% & - & 58.3 & 74.3 & 13.3 & 0.66 \\
\hline Proportion of calves with no previous BRD affected by BRD, \% & 23.8 & 30.6 & 43.3 & 9.6 & 0.10 \\
\hline Total number of BRD cases/hutch & $3.7^{\mathrm{c}}$ & $5.2^{\mathrm{b}}$ & $7.8^{\mathrm{a}}$ & 1.1 & 0.02 \\
\hline Number of BRD cases/hutch (for calves with previous BRD before grouping) & - & $5.2^{\mathrm{b}}$ & $8.8^{\mathrm{a}}$ & 1.2 & 0.04 \\
\hline Time to first BRD case, d (for calves with previous BRD before grouping) & - & 7.9 & 8.1 & 8.2 & 0.98 \\
\hline Time to first BRD case, $\mathrm{d}$ (for calves with no previous BRD before grouping) & 19.1 & 11.7 & 11.9 & 3.2 & 0.07 \\
\hline Time elapsed between first and second BRD, d & 16.6 & 10.8 & 11.2 & 3.7 & 0.54 \\
\hline $\begin{array}{l}\text { Time elapsed between first and second BRD, d } \\
\text { (for calves with previous BRD before grouping) }\end{array}$ & - & 11.2 & 6.6 & 2.4 & 0.38 \\
\hline $\begin{array}{l}\text { Time elapsed between first and second BRD, } \mathrm{d} \\
\text { (for calves with no previous BRD before grouping) }\end{array}$ & 16.6 & 10.7 & 14.5 & 4.3 & 0.27 \\
\hline
\end{tabular}

${ }^{\mathrm{a}-\mathrm{c}}$ Means with different superscripts within a row differ at $P<0.05$.

${ }^{1} \mathrm{HHH}=$ group of 8 calves with no previous BRD cases; HHR = group of 6 calves without and 2 with a previous BRD history; HRR = group of 5 calves without and 3 with a previous BRD record.

${ }^{2}$ Effect of grouping strategy.

sively increased $(P<0.05)$ from HHH to HRR as the proportion of calves previously affected by BRD within super hutch increased (Table 1), mainly due to the fact that both animals affected by BRD before weaning and those with no previous history of BRD had more ( $P$ $<0.05)$ relapses in HHR and HRR groups than in the HHH group (Table 1). Therefore, it could be concluded that morbidity increased as the proportion of calves with a previous case of BRD within hutch increased.

The average time elapsed between commingling the animals and the appearance of the first BRD case (Table 1) was shorter $(P<0.05)$ when calves with a $\mathrm{BRD}$ episode prior to weaning were present in a group after weaning $(10.8 \pm 3.3 \mathrm{~d})$ than when the group was formed with calves that had never experienced BRD before weaning $(22.5 \pm 3.3 \mathrm{~d})$. Step et al. (2008) reported that time to first respiratory treatment was $7 \mathrm{~d}$ for steers coming from different origins, $11 \mathrm{~d}$ when mixing animals from one origin with those from other origins, and $18 \mathrm{~d}$ when calves were grouped within origin. However, in their study, it was not known whether calves being grouped had experienced a prior BRD case. Nevertheless, it is interesting to note that the time elapsed between commingling animals and the first appearance of BRD was similar in young calves (current study) and 8-mo-old heifers (Step et al., 2008). In the current study, the decrease of time to first BRD in HHR and HRR groups in comparison with HHH calves was mainly due to a tendency $(P=0.07)$ for calves without previous BRD history in the HHR and HRR groups to suffer a BRD case about $7 \mathrm{~d}$ before those in the $\mathrm{HHH}$ group (Table 1). This result could be attributed to the increased number of BRD relapses observed in calves with a previous case of BRD that could have elicited the appearance of BRD in those animals with no former BRD history. Overall, no differences were observed among groups on the time elapsed between a first and a second case of BRD (Table 1), which was also in agreement and within the range reported elsewhere (Step et al., 2008).

No differences in calf performance were observed among the evaluated grouping strategies (Table 2). However, a tendency $(P=0.09)$ existed for the number of BRD cases a calf incurred to affect negatively ADG and final BW at $115 \mathrm{~d}$ of age (Figure 1). In fact, the difference in final BW between calves that never incurred BRD $(142.8 \pm 3.3 \mathrm{~kg})$ and calves that had 3 or more BRD cases after grouping $(131.6 \pm 6.2 \mathrm{~kg})$ was about 11 $\mathrm{kg}$ (Figure 1). These results are in agreement with the observations from Stanton et al. (2010) who reported that final BW (at about $100 \mathrm{~d}$ of age) was decreased by about $8 \mathrm{~kg}$ if a calf incurred BRD after grouping.

\section{Experiment 2}

Separating calves with a BRD record from those with no previous BRD history before weaning increased overall BRD incidence after grouping (Table 3). As it occurred in experiment 1 , the number of BRD cases per hutch was greater $(P<0.05)$ in the RRR than in the HHH groups, and calves in the RRR group experienced BRD earlier $(P<0.05)$ than did calves in the $\mathrm{HHH}$ group (Table 3), but no differences were found in the elapsed time between a first and a second BRD case. These results support the observations from experiment 1 and further reinforce the concept that calves 
Table 2. Effects of clinical respiratory history of individually housed calves on growth performance after grouping (experiment 1)

\begin{tabular}{lccccc}
\hline & \multicolumn{3}{c}{ Grouping strategy $^{1}$} & & \\
\cline { 2 - 4 } Item & HHH & HHR & HRR & SE & $P_{\text {-value }}{ }^{2}$ \\
\hline Initial BW, kg & 72.2 & 73.1 & 72.4 & 1.18 & 0.28 \\
Initial age, d & 58.4 & 58.9 & 58.3 & 0.77 & 0.67 \\
Final BW, kg & 141.7 & 137.8 & 137.7 & 3.98 & 0.90 \\
Final age, d & 114.1 & 115.2 & 114.6 & 0.98 & 0.32 \\
ADG, kg/d & 1.25 & 1.15 & 1.16 & 0.05 & 0.20 \\
\hline
\end{tabular}

${ }^{1} \mathrm{HHH}=$ group of 8 calves with no previous BRD cases; HHR = group of 6 calves without and 2 with a previous $\mathrm{BRD}$ history; HRR = group of 5 calves without and 3 with a previous BRD record.

${ }^{2}$ Effect of grouping strategy.

that had incurred a BRD while individually housed were more susceptible to have a second case after being commingled with other calves.

Calves in the HHH group reached a greater $(P<$ $0.05) \mathrm{BW}$ at the end of the study than did those in the RRR group (Table 3 ) as a consequence of a tendency $(P=0.07)$ for a greater ADG during this period.
Furthermore, the ADG observed in calves in the RRR group in experiment 2 and that observed in calves in the HHR and HRR groups in experiment 1 were similar (about $1.15 \mathrm{~kg} / \mathrm{d}$ ), but lower than the ADG observed in the HHH groups in both experiments. Therefore, it could be reasoned that previously BRD-affected calves should be raised in a single group, and calves not pre-

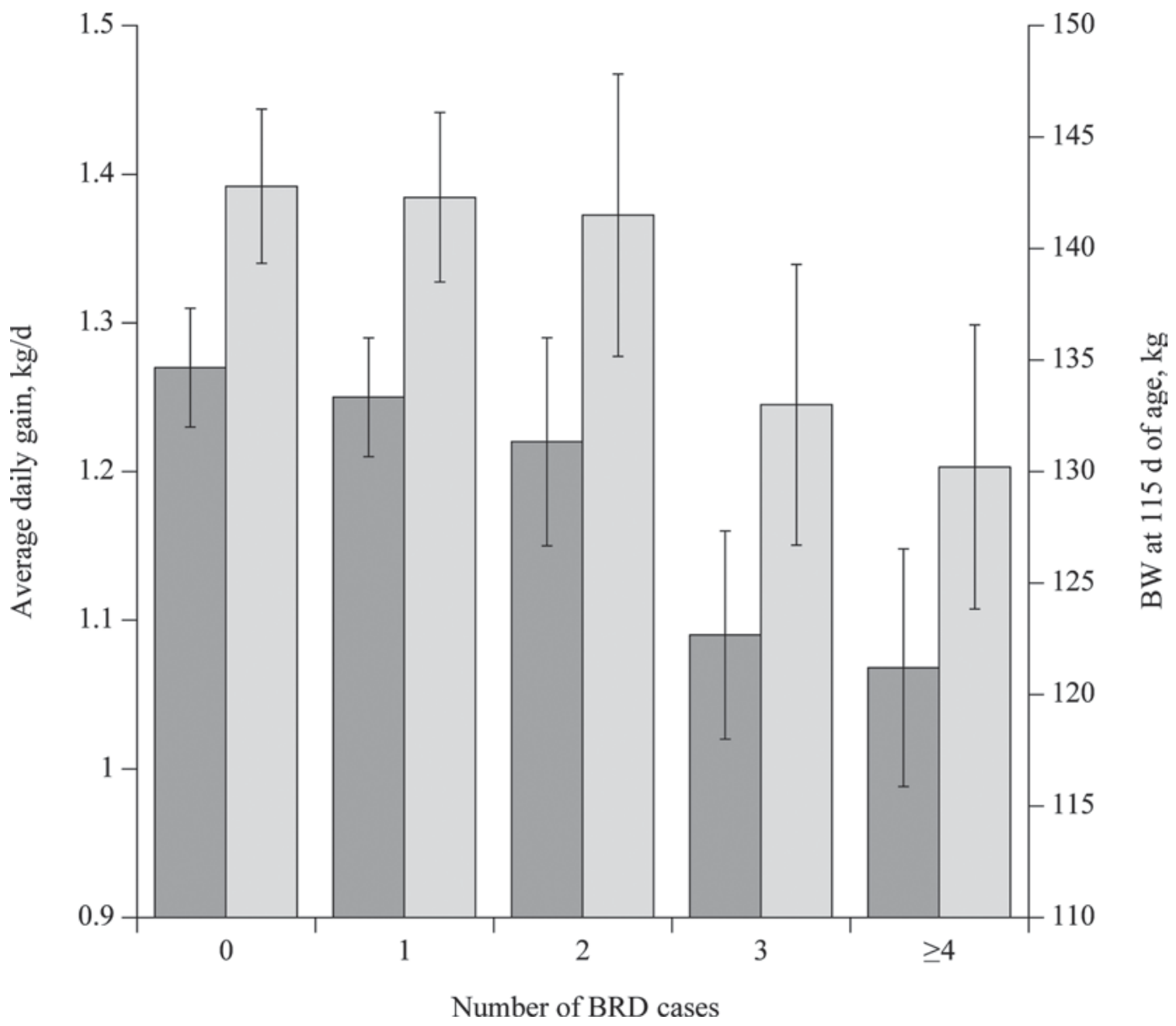

Figure 1. Effect of number of bovine respiratory disease (BRD) cases after grouping young calves on growth performance (dark gray) between 58 and $115 \mathrm{~d}$ of life and BW (light gray) at $115 \mathrm{~d}$ of age (experiment 1 ). 
Table 3. Effects of clinical respiratory history of individually housed calves on incidence of bovine respiratory disease $(\mathrm{BRD})$ and growth performance after grouping (experiment 2)

\begin{tabular}{|c|c|c|c|c|}
\hline \multirow[b]{2}{*}{ Item } & \multicolumn{2}{|c|}{ Grouping strategy ${ }^{1}$} & \multirow[b]{2}{*}{$\mathrm{SE}$} & \multirow[b]{2}{*}{$P$-value 2} \\
\hline & $\mathrm{HHH}$ & RRR & & \\
\hline \multicolumn{5}{|l|}{ Respiratory afflictions } \\
\hline Proportion of calves affected, $\%$ & 37.5 & 98.6 & 5.10 & $<0.001$ \\
\hline Total number of BRD cases, per hutch & 4.5 & 11.3 & 2.03 & 0.01 \\
\hline Time to first BRD case, d & 19.3 & 9.3 & 1.96 & 0.01 \\
\hline Time elapsed between first and second BRD, $\mathrm{d}$ & 16.6 & 16.0 & 4.72 & 0.92 \\
\hline \multicolumn{5}{|l|}{ Performance } \\
\hline Initial BW, kg & 72.6 & 72.3 & 0.94 & 0.88 \\
\hline Initial age, $\mathrm{d}$ & 57.9 & 58.0 & 0.49 & 0.87 \\
\hline Final BW, kg & 141.3 & 136.3 & 2.73 & 0.01 \\
\hline Final age, $\mathrm{d}$ & 114.7 & 114.7 & 0.46 & 0.98 \\
\hline $\mathrm{ADG}, \mathrm{kg} / \mathrm{d}$ & 1.21 & 1.13 & 0.06 & 0.07 \\
\hline
\end{tabular}

viously affected by BRD would perform better if not mixed with calves with a previous history of BRD.

\section{CONCLUSIONS}

Calves with a history of respiratory disease are more likely to have BRD relapses after grouping than those with no previous record, and morbidity increases when calves with and without previous history of respiratory disease are commingled. Segregating animals with previous respiratory history should minimize postweaning incidence of respiratory cases in calves not previously affected by respiratory problems before grouping.

\section{ACKNOWLEDGMENTS}

The authors thank the Spanish Ministry of Industry, Tourism, and Trade through the CDTI (Centro para el Desarrollo Tecnológico Industrial, Madrid, Spain) for partial funding of this study through the project number IDI-20080836. Special thanks to Vicente García from Rancho Las Nieves (Mallén, Spain) for his pivotal role in the organization and combination of routine activities of Rancho Las Nieves and the tasks imposed by these research studies, and to Ana Ramillete, also from Rancho Las Nieves, for her meticulous assistance with data handling.

\section{REFERENCES}

Bach, A., and J. Ahedo. 2008. Record keeping and economics of dairy heifers. Vet. Clin. North Am. Food Anim. Pract. 24:117-138.
Bach, A., J. Ahedo, and A. Ferrer. 2010. Optimizing weaning strategies of dairy replacement calves. J. Dairy Sci. 93:413-419.

Berge, A. C., T. E. Besser, D. A. Moore, and W. M. Sischo. 2009. Evaluation of the effects of oral colostrum supplementation during the first fourteen days on the health and performance of preweaned calves. J. Dairy Sci. 92:286-295.

Martin, S. W., and A. H. Meek. 1986. A path model of factors influencing morbidity and mortality in Ontario feedlot calves. Can. J. Vet. Res. 50:15-22.

Sivula, N. J., T. R. Ames, W. E. Marsh, and R. E. Werdin. 1996. Descriptive epidemiology of morbidity and mortality in Minnesota dairy heifer calves. Prev. Vet. Med. 27:155-171.

Stanton, A. L., D. F. Kelton, S. J. LeBlanc, S. T. Millman, J. Wormuth, R. T. Dingwell, and K. E. Leslie. 2010. The effect of treatment with long-acting antibiotic at postweaning movement on respiratory disease and on growth in commercial dairy calves. J. Dairy Sci. 93:574-581.

Stata Corporation. 2006. Stata/SE 9.2 for Macintosh. Stata Corp., College Station, TX.

Step, D. L., C. R. Krehbiel, H. A. DePra, J. J. Cranston, R. W. Fulton, J. G. Kirkpatrick, D. R. Gill, M. E. Payton, M. A. Montelongo, and A. W. Confer. 2008. Effects of commingling beef calves from different sources and weaning protocols during a forty-two-day receiving period on performance and bovine respiratory disease. J. Anim. Sci. 86:3146-3158

Svensson, C., and P. Liberg. 2006. The effect of group size on health and growth rate of Swedish dairy calves housed in pens with automatic milk-feeders. Prev. Vet. Med. 73:43-53.

Svensson, C., K. Lundborg, U. Emanuelson, and S. O. Olsson. 2003. Morbidity in Swedish dairy calves from birth to 90 days of age and individual calf-level risk factors for infectious diseases. Prev. Vet. Med. 58:179-197.

Virtala, A. M. K., G. D. Mechor, Y. T. Gröhn, and N. H. Erb. 1996. Morbidity from nonrespiratory diseases and mortality in dairy heifers during the first three months of life. J. Am. Vet. Med. Assoc. 208:2043-2046.

Wittum, T. E., and L. J. Perino. 1995. Passive immune status at postpartum hour 24 and long-term health and performance of calves. Am. J. Vet. Res. 56:1149-1154. 